\title{
Research on the tourism industry transformation of the northwest region of Yunnan Province from the perspective of extension marketing theory
}

\author{
Cai Zhan, DingLin \\ Tourism and Culture College of Yunnan University 674100
}

\author{
Keywords: Extension marketing Yunnan Tourist industry Transformation
}

\begin{abstract}
This paper mainly in northwest Yunnan as an example, discussing the mode of the tourism industry transformation and upgrading, Core content is the extension of marketing theory to specific guidance and application of northwest yunnan tourism industry on the basis of the five contents of extension marketing theory, from five aspects to promote the transformation and upgrading of the tourism industry development in northwest yunnan. This paper is a research project of the Yunnan Provincial Department of education scientific research fund in 2015, the project number is $2015 \mathrm{Y} 508$.
\end{abstract}

\section{Extension marketing theory overview}

Extension marketing research began at the end of the twentieth Century, by the Chinese scholar Yang Chunyan and Cai Wen [1] first proposed, extension marketing is based on the theory of extension theory, with extension method as a tool, innovation as the core, combined with the modern marketing theory [2] and the management thought of the ancient and modern times in China, put forward to create products - to open up the market - innovative enterprises as the main line of marketing ideas.It makes use of the extension, extension transformation and extension set to deal with various problems in the marketing process. Extension marketing and traditional marketing biggest difference is that extension marketing innovation. Innovative results include new products, new markets, new resources, new planning, and even new business. Extension study is a cross subject, its basic theory is the extension theory, the special method is the extension method.

The study began in 1976 and published the first paper in 1983. At present, a preliminary theoretical framework has been formed. Among the many extension methods, one of the most comprehensive and systematic research is the extension of marketing. At present, the extension application of marketing in the tourism industry is very broad and common. The extension marketing of real estate and tourism industry has been studied by scholars.Scholars of real estate and the tourism industry extension marketing was studied, however, about the extension application of marketing in the theoretical study of tourism development is very small, there is no fully the extension marketing and tourism combine good, nor the extension marketing innovative ideas into concrete development of the tourism industry. So the future may also be extension application study in the field of marketing in other industries

\section{The development of tourism industry in Northwest Yunnan}

\subsection{Rich tourism resources}

Northwest Yunnan has unique tourism resources, and rich in types, it located in the Yunnan Guizhou Plateau and the Qinghai Tibet Plateau with the Department, has the unique landform, and Tibetan culture and Han culture, local culture syncretism office, the formation of a complete type in this region and distinctive tourism resources. Tourist area in the northwest of Yunnan, the unique characteristics of the tourism resources in attracting worldwide tourists eager to come, with three parallel rivers Pentium, three grand canyon grand, Meili Snow Mountain and the Yulong Snow Mountain, the snow capped mountains towering, rare variety of flora and fauna landscape, have shocked the world of national culture, the natural landscape and cultural landscape of the inclusive, 
these for the development of tourism industry in the northwest region of Yunnan Province provides a solid resource security.

Many of them are national scenic area, national historical and cultural city, nature reserve and a number of national, provincial, prefecture and county of key cultural relics protection unit, such as the ancient city of Lijiang, Dali, the ancient city of Weishan are the historical and cultural city in the world. The tourism resources in some not only has the province, the national first-class level, but also has a certain reputation in the world, such as the Naxi ancient music to complement and innovation of the music culture in the world.

\subsection{Present situation of tourism development}

Tourism development in the northwest region of Yunnan Province, has basically formed a variety of levels of various types, the structure tends to be a reasonable mode of tourism.

Dali Tourism: tourism resources mainly include: Cangshan Mountain and Erhai Lake, Nanzhao customs Island, butterfly spring, Jizu mountain natural landscape and the Chongsheng temple, Bai houses, Bai "Raosanling" etc. cultural resources. Dali tourism development is relatively early, high visibility, perfect tourism infrastructure, these are the development of tourism in Dali has laid a good foundation

Lijiang tourism: tourism resources mainly include: cultural landscape of the Yulong Snow Mountain, Tiger Leaping Gorge, Lugu Lake, pull the city of the sea etc. the natural landscape, the old town of Lijiang, Naxi ancient music, Dongba culture. Although Lijiang tourism started late, but the development speed is very fast, at present in the northwest of Yunnan tourism area is high, become a new tourism hot spot area.

Diqing tourism area: the natural landscape are: Pudacuo, Meili Snow Mountain, Balog Zon etc. and humanistic landscape main: Songzanlin temple, Tibetan folk customs, tourism resources relatively more abundant. In recent years, the government attaches great importance to the economic effect brought by the tourism, vigorously develop tourism, the infrastructure needs to be improved.

Nujiang tourism area: here are famous world natural heritage three parallel rivers wonders, and unique characteristics of the Lisu ethnic customs, natural and humanistic add radiance and beauty to each other. The development of Nu River tourist area is also relatively late, coupled with the economic backwardness, poor transportation, the development of the tourism industry is very difficult.

Overall, area of the northwest of Yunnan Province tourism industry a good momentum of development, in recent years is the rapid development trend, but in the long run, the development of tourism in the region exist many problems, which need to be solved urgently: (1)The tourism resources in the development of the tourism industry status is not clear, the tourism product homogeneity serious; (2) The tourism market confusion, failed to do market segmentation; (3) In the tourism development did not deal with good developing resources and protecting the environment; (4) Tourism enterprises is still too weak, did not form a cohesive force; (5) Scenic area marketing and publicity is not in place, did not do creative planning.

\section{Extension marketing theory applied to the tourism industry in the northwest of Yunnan Province.}

\subsection{Theoretical significance}

Here was a history of the famous "tea horse road" of the fortress, which is also in Yunnan Province is relatively poor ethnic minority inhabited areas, in the long historical development, all ethnic groups each other frequently for economic and cultural exchanges, the formation of the a unique "cultural corridor", has a very unique human landscape, folk customs and unique natural geographical features is an excellent resource for the development of the tourism industry. Choose special location, economic and social conditions, can rely on the advantages of the border ethnic cultural resources, the development of eco friendly tourism industry. How to better play the advantages of national culture, promote the healthy development of the tourism industry, the tourism industry in Northwest Yunnan Province is an urgent problem to be solved. In the rapid 
development of information technology, enterprise competition and increasing customer needs become more diversified and heterogeneous environment. This topic using extension marketing theory, for tourism enterprises product innovation, market development, expand resources can provide the theoretical basis for the operation. The use of interdisciplinary research methods, theoretical innovation, is a new perspective of national tourism research, is conducive to the rich tourism industry related theory.

\subsection{Realistic meaning}

Try to use extension marketing theory, is conducive to the transformation and upgrading of the tourism industry, is conducive to promoting the development of the western region, accelerate the development of ethnic minority areas in the border areas, to solve the problem of uneven development of the national economy. These years, in northwest of Yunnan Province tourism industry in Dali, Lijiang as the center, has achieved great development, but now also encountered the bottleneck of the development, such as location block, traffic conditions are poor, low level of industrialization, industrial supporting ability is poor, the tourism products the same high, poor innovation of tourism enterprises, low quality of personnel engaged in tourism, tourism marketing channel is narrow, the destruction of the ecological environment and so on, tourism industry transformation and upgrading is imperative. At the same time, the extension and application of marketing theory only with the combination of specific industries, but also to do theory to guide practice, embodies the theory of value; tourism industry under the guidance of the theory, in order to play better economic benefits. We try to apply the extension marketing theory to the development of tourism industry in the context of the current wisdom tourism, making it an important path to promote the transformation and upgrading of tourism industry in the northwest of Yunnan province.

\section{Extension marketing theory applied to the tourism industry in the northwest of Yunnan Province}

\subsection{Product extension marketing}

By extension of matter element on the need for a formal representation, and research needs of the extension of the formal analysis methods are needed, so as to provide formal ideas from the need of creating new products, to facilitate product development design of new products; by extension analysis of products, to study the product development the law, and according to the conjugate product, provide complete products to meet the needs of the concept; from the perspective on the classification of products, according to different types of products, make product innovation in different ways; according to the extension of the divergence of the products can be, and then use the superiority evaluation method of convergence, and finally get the product design available. The product conception rhombus thinking mode, make the product innovation activities according to law.

Of tourism products of extension analysis, the extension of rhombus thinking is needed in order to better extension of the life cycle, give full consideration to the relation between the change of products and technology, society, economy, environmental protection and time, so as to enhance the tourism product portfolio breadth, depth and degree. Tourist attractions implement product innovation, in essence, is a kind of brand extension strategy, formal methods to form extensive marketing innovative products by product. Lijiang Jade Dragon Snow Mountain scenic area, for example, refers to the implementation of high-quality brands of scenic spots around the other perfect scenic product coverage, and ultimately the formation of a jointly owned famous brand tourism group. In this way, not only can the Yulong tourist area famous brand bigger and stronger, highlighting the tourist area tourism product quality and diversity, can also through the effect of radiation driven other scenic spots around the development and to create a good brand association.

\subsection{Marketing extension marketing}

Sales of tourism products only in a specific market is a one-sided view, not only to try to retain existing markets, should also be based on the existing market, by changing the conditions, such as inspire visitors to purchase motivation and increase the tourists purchase way, the dispersion of 
tourists to buy time to expand the potential market. For example: Yunnan tourists want to travel to Thailand, all the people in Yunnan want to go and have the ability to go to Thailand are the extension of the market. By some transformation conditions, such as ticket prices, increased holidays, visa free can makes the original don't want to go, do not have the ability to or have no way to Thailand to successfully enter the market, these people constitute the new collection for the original market extension market. The same tourism products, for different tourism market, you can choose the regional tourism brand strategy.

For example: the famous Zhangjiajie scenic area not only focuses on the development of domestic tourism market, or even look into the foreign, pay attention to the foreign tourist market marketing, which is an important source country for South Korea. Northwest Yunnan tourist attractions, the famous large attractions are often overcrowded, and visibility is not high but resources are better area but few people interested. This relates to the tourism market development efforts is not balanced, goal is not clear, need extensive marketing, the "hidden in purdah did not know" the scenic resources better marketing to the market on the market, extent can change the current in the northwest of Yunnan tourism market structure.

\subsection{Extension marketing of resources}

In the tourism resource attraction to frequency "depletion" of the "consumption" era, is also one of the ways to transform the breakthrough of tourism resources. In other words, tourism resources are not absolutely stationary, with the elapse of time, things change and developments, category and the types of tourism resources in the development and change, value and function in expanding and extending, structure and also can contact transformation and transformation. [3] From the development of material heritage to intangible heritage development, from single resource development to integration of resources, from a development to secondary development, whether natural tourism resources, or cultural tourism resources, with the arrival of the era of tourism development, need of resources for development, dig resource of the intrinsic charm.

In the "post consumption" era, the transformation is also one of the ways to break through the limitation of tourism resources. In other words, tourism resources are not absolutely stationary, with the elapse of time, things change and developments, category and the types of tourism resources in the development and change, value and function in expanding and extending, structure and also can contact transformation and transformation. With the arrival of the era of tourism development, it is necessary to open up resources, in-depth exploration of the inherent charm of resources. In the northwest of Yunnan Province tourism resources can be described as unique, but with the rapid development of tourism attraction trends to be depleted, the region also in resources to explore the intrinsic charm, such as area of the northwest of Yunnan Province "impression of Lijiang", "Yimiyangguang", "riding alone for thousands of miles" and so on film and television works, the form is too simple, do not fully explore the connotation of resources.

\subsection{Extension marketing of enterprises}

The competition of Chinese enterprises has experienced the stage of product competition, price competition, quality competition, service competition, brand competition and image competition. In the stage of ability competition, enterprises need to enhance the ability of a full range of ability, especially the ability to expand the most critical. In an enterprise, there are all kinds of forces: enterprise financial resources, enterprise power, enterprise intelligence, enterprise emotional force, enterprise name. Only in a variety of power of the original foundation, fully tap the potential of their deep-seated, and to properly deal with the relationship of all kinds of force, they can play a biggest role, enterprises can be more sound and sustainable development and growth. This behavior is the extension of enterprise marketing.

Zhejiang Hengdian movie and television city successfully from the single business "film base and tourism to build the strategic change of movie and TV tourism theme park, it is implementation of the enterprise can be extensive marketing strategy, the internal enterprises of various force to optimize the combination. Northwest region of Yunnan Province, there is no lack of practice strong tourism enterprises, such as the major travel agencies, the hotel, group of each big scenic spot, each big travel transportation companies, and how to be successful with by a single operation to multi 
operation, how to optimize the combination of internal force, force on the market, how to better promote frontier minority area tourism economy development, need to make full use of corporate extension marketing strategy.

\subsection{Planning extension marketing}

In extension marketing planning, people want to break away from the bondage of the inertia of thinking, and only the divergent thinking methods, in order to obtain a variety of options, then priority degree evaluation method for screening, finally determined the optimal scheme. The basic idea of extension of marketing planning: selection of unique items, select the appropriate strategy, the organic integration of resources, to determine the "four two sets of the millennium," the key strategy.

Marketing planning can be extended to the basic idea of: select the unique project, choose the right strategy, the organic integration of resources, to determine the "four two sets of the millennium," the key strategy. In recent years, celebrity effect, the effects of the media has always been large-scale influence, such as " Five Alliance " Jin Yong reinstated not only won the eyeball, gathered popularity, and put forward the development strategy of the integration of resources, joint marketing, but also for future marketing activities to create space [4]. These are the concrete practice of planning can be extensive marketing involving to Northwest Yunnan is how best to gather popularity, attract eyeball, through tourism planning is unique in China's tourism industry, the same is need to think and to be solved problems. For example, tourism plight in the old town of Lijiang encounter, part and advocate affair cultural associations, after many years of practice and verification, the culture has been too vulgar and obsolete.

\section{Reference}

[1] Cai Wen, Yang Chunyan.Extension marketing[M].Beijing Science and Technology Literature Publishing House, 2000

[2]Philip Kotler.Marketing Management-Analysis, Planning and Control. Prentice-Hall[J].International Inc.1997

[3] Li Qinglei, Zhao Hongmei. Extension of tourism resources and its epistemological significance [J], Human geography, 2012, (3): 125 130.

[4] Li Qinglei, Liao Chunhua, Liang Caixia. Tourism creative marketing: The innovation and development of tourism marketing theory of consumption society [J]. Journal of hubei university of economics, 2011, (9):74 80.

[5] Yang Chunyan, He Bin, Cai Wen. Research on extension marketing theory [J]. Practice and understanding of Mathematics, in 200106.

[6] Cai Wen. Extension marketing [M]. Beijing: Science and Technology Literature Publishing House, February 2000.

[7] Wan Lun, Zhang Shu Lin. Based on the matter element analysis of the tourism market, "diffusion" marketing -- in Nanchuan City tourism marketing as an example [J]. Southwest China Normal University Journal (NATURAL SCIENCE EDITION), 2005 issue 01

[8] Wan Lun. Extension of tourism planning research: a new vision of tourism planning based on extension [D]. Chongqing Normal University, 2005.

[9] Zhang Xiaolin, Luo Xiaojun, Yang 1. Sports tourism based on matter element analysis can expand marketing strategy research [J]. Journal of Capital Institute of Physical Education, 200601.

[10] Wei Zhongjun, Zhou Ming dispute, Liu Tao. Sustainable development of tourism and cultural industry extension model [J]. Journal of Harbin Institute of Technology, 200612.

[11] Lv Wenyi, Li Qinglei, Wang Feng, Zouping. Study on the mechanism of tourism creative generation based on extension theory [J]. Journal of Beijing International Studies University, 9, 
2011.

[12] Zhao Jianjun. Research on tourism development in Northwest Yunnan [M]. Kunming: Publishing House of Yunnan University, 2009

[13] Zheng Yuan same. Study on regional tourism cooperation under the vision of tourism resources integration [M]. Chengdu: Publishing House of Southwestern University of Finance and Economics, 2009

[14] Zhang Yaping. Investigation on the utilization and protection of tourism resources in the northwest of Yunnan Province [N], Yunnan economic daily, 2005, (1).

[15] Li Gang. A discussion on the development of minority cultural tourism in Northwest Yunnan [J]. Journal of Dali University, 2003, (3):30-33.

[16] Weng Lili. The development of tourism resources in the northwest of Yunnan my view on the problem of the [J]. consumer guide, 2008, (1):1.

[17] Zhao Jianjun. Tourism transformation in the northwest region of Yunnan Province Economic hotel development strategy [J]. China development, 2009, (3):77-79.

[18] Zhang Jianxiong. A comparative analysis of three models [J]. Journal of tourism, tourism resources development in Northwest Yunnan 2002, (5):21-53.

[19] Liu Li. Construction of the northwest of Yunnan Province to promote the two pioneering [N]. China Tourism News, 2006, (1).

Author introduction:

Cai Zhan, female, lecturer, master's degree. The main research direction is the regional tourism planning. Tourism and Culture College of Yunnan University. Deputy director of the Tourism Management Department of travel agency management.

Ding Lin, male, Professor. Tourism and Culture College of Yunnan University.Executive deputy director of Centre for tourism development research. 